\title{
An Empirical Study of Chinese Haze and Influencing Factors Grey Correlation Analysis of 30 Provinces in China between 2000 And 2015
}

\author{
TONG Xin \\ School of Economics \\ Central University of Finance and Economics 100081 \\ School of Business Administration \\ Northeastern University 110819 \\ LI Xuesen \\ 3. College of science and technology \\ Shenyang Polytechnic College \\ Shenyang 110021 \\ TONG Lin \\ Department of Engineering Technology \\ Dalian Maple Leaf College of Technology \\ Dalian 116036 \\ LIU Peigang \\ Beijing Municipal Institute for Economic and Social Development
}

\begin{abstract}
The degree of association between haze and influencing factors determines the correct decision and grasp the decision-making path of haze governance. In this paper, the gray system theory correlation research method was used to comparative analysis 30 provinces haze and relevance factors of China have different effects. Industrial structure is still the leading cause of haze increased from China's overall; Absolute correlation degree higher energy prices and most provincial haze and fiscal decentralization, and comprehensive grey correlation degree is low; The stage of economic development and economic development situation, haze and correlative factors of different effects so they cannot adopt the nationwide unified haze governance policies. Finally, this paper discusses the haze governance strategy of China's future green development on the basis of the research results, and puts forward the countermeasures and suggestions for haze governance according to different characteristics.
\end{abstract}

Keywords: Haze- Influencing factors. Grey Correlation Analysis

\section{Introduction}

General secretary Xi Jinping of China pointed out that China should be an important participant, contributor and leader in the construction of the global ecological civilization at the nineteen report. We can see the consciousness and initiative of our country to carry out the concept of green development, and point out the shortage of our work, the protection of the ecological environment far away, and many short boards in the field of people's livelihood. The construction of ecological civilization is a millennium plan for the sustainable development of the Chinese nation. As a matter of people's livelihood, fog and haze environmental pollution has attracted great attention of our government, and some measures have been taken to achieve certain results. Haze is a mixture of fog and haze, and the China Meteorological Administration "ground meteorological observation code" indicates that fog is an aerosol system, a product of condensation of water vapor suspended in the air.

Haze, also known as haze, is made up of particles of sulfuric acid, organic hydrocarbons or dust suspended in the air, resulting in turbidity in the air. Haze weather refers to a state of air pollution. Fog and haze is a general

This work is funded by China Scholarship Council; China Postdoctoral Science Foundation, Project approval number: 2016M601240; Liaoning Social Sciences Joint Economic and social development research topics, Project approval number: 20191slktyb-005; Doctoral foundation of Northeastern University at Qinhuangdao, Project approval number: XNB201704; 2018 
description of the suspended particles in the atmosphere. The primary task of controlling haze pollution is to control PM2.5. The PM2.5 index refers to the content of particles in the atmosphere less than 2.5 microns in diameter, and is also the culprit of the fog and haze weather. In recent years, under the five development concepts of innovation, coordination, green, open and sharing, the governments at all levels have made a lot of efforts to control the haze. At the same time, we should also see that the formation of haze has a complex cause, so we should realize the strategic goal of building beautiful Chinese and national sustainable development. The treatment of haze is a long-term and arduous process. It is necessary to adopt a scientific method to reduce the fog and haze pollution and reduce the negative effects of haze on people's healthy life.

\section{Literature review}

Foreign scholars began to study haze from 1970s, mainly using quantitative research methods to study energy structure from the perspective of energy consumption. For example, Crorapton and other scholars believe that energy structure changes and economic growth have a direct relationship with energy consumption (Crorapton et al.2005; Solow R M 1957). Nurhidayah and other scholars put forward a good legal framework from the legal point of view for the haze control (Nurhidayah2013). Jones and other scholars have proposed that the internal structure of industry has an important impact on the total energy demand and energy structure, thus affecting the environment change(Jones et al.1995), Frank and other scholars believe that economic agglomeration is an important lure for environmental pollution(Frank et al. 2001; Selden T M et al.1995). The study of haze pollution in China began mainly in 1990s, Hui Ying and other scholars pointed out that strengthening the construction of local government is an effective means to solve the increasingly serious fog and haze pollution from a political point of view (Hui Ying et al. 2018; Li Bin 2012). Zheng Guojiao and other scholars analyze the causes of the fog from the perspective of economic development, and put forward the reasons for the fog he measures to establish regional inter government cooperation mechanism (Zheng Guojiao et al. 2015; Tong Xin 2017). Li Zhenyu and other scholars analyze the causes of fog and haze in Beijing, Tianjin and Hebei Province from the energy structure angle (Li Zhenyu et al.2013; Li Kaijieet al. 2012). Wang Meixia analyses the main driving factors from different influence factors of haze pollution, and puts forward the haze of comprehensive control measurement (Wang Meixiaet al. 2017). Ma Limei and other scholars believe that China's change in coal-based energy consumption structure and optimize the industrial structure is the key to smog control (Ma Limei et al. 2014). Wu Xun and other scholars have made an empirical analysis on the spatial characteristics and influencing factors of haze accumulation in China, and study the effect of economic development level and industrial structure adjustment on haze control (Wu Xunet al. 2015). Wang Yichen and other scholars analyzed the spatial correlation characteristics of fog and haze and the spillover effects of influencing factors in Beijing-Tianjin-Hebei region, and put forward corresponding policy recommendations (Wang Yichen2017). LengYanli and the other scholars have studied the effects of energy price distortion on the environment pollution in the province of China (LengYanli et al. 2016; Li Jian 2012). The results show that the energy price distortion has a positive effect on the effect of haze pollution, and the positive effect of energy price distortion on haze pollution in the eastern region is greater than that in the middle and western regions. Zhuang Guiyang and other scholars systematically studied the theoretical foundation and institutional innovation of Beijing Tianjin Hebei synergistic governance, and pointed out that "the top level design, the consistency of the target, the distribution of interests and the sharing of information" is the order parameter to promote the governance of the fog haze system (Zhuang Guiyang et al. 2012). It can be seen that environmental governance is a systematic project. Fog and haze pollution is a complex problem, and there are many aspects involved. The more than 30 provinces of China are different in specific environment. Therefore, different influence factors of different provinces and haze are different. The new subject of grey theory can meet these conditions and is widely used in environmental research to analyze and solve practical problems, and there is no systematic study on the mechanism of different influence factors of haze and haze in 30 provinces of China. This paper first determines the fog and haze quantity and the main influencing factors, the correlation between provincial haze and main factors provide theoretical basis for haze control in different regions and uses the grey theory to analyze the different China.

Model and data

\section{Data}

Haze has become an important research topic in the field of China green economic construction, and it is also a major problem involved in the coordinated development of all countries in the world. It is the key to accurately 
calculate the haze quantity of our country. In this paper, we use the available data from the haze at home and abroad. Most of the research uses the PM 2.5 year concentration value of the aerosol optical thickness measured by the satellite launch equipment of Columbia University. Therefore, this study also refers to the data and is combined with the monitoring data of the Environmental Protection Bureau of China so the data of fog and haze is very reliable.

We have determined nine influencing fogs factors of population, economic growth, technological progress, industrial structure, financial development, energy price, international trade, urbanization rate and fiscal decentralization according to the special national conditions of our country considering the availability and integrity of the data, and drawing on the research results of scholars about haze at home and abroad to empirical research the grey correlation among haze and the main various influencing factors in different regions of China.

Population (P): Population is a complex social entity which integrates many kinds of social relations. It has many kinds of social constitutions, social relations, economic constitutions and economic relations. All social relations, social activities and social problems are related to the process of population development. Population is the basis and main body of social production activities, but different levels of economic development, different social development conditions and different process of population development, people are different in understanding and reflecting the phenomenon of population. Generally speaking, the number of population has a positive impact on environmental pollution. The more people are, the more energy they consume and the more pollutants they produce. But in real life, with the development of technology and the improvement of people's awareness of environmental impact, population indicators have a negative impact on environmental pollution, and because of the different development conditions of the region, the mechanism of the effect of population to the environment is different.

Economic growth (A): Economic growth is a measure of the scale and speed of national and regional economic development, and is the standard of economic development stage and potential. It is usually used to reflect the economic development level of a country or region, such as national income, economic development speed, gross national product, per capita national income and economic growth rate. Economic development requires a large amount of energy input, energy consumption may cause pollutants and environmental pollution at the same time. However, with the development of the economy, the change of people's consumption concept, the quality of life and the high quality of the environment, the public is more interested in the purchase of green products, thus promoting the adjustment of the industrial structure, eliminating the backward industries and enterprises with high energy consumption and high pollution, and developing the third industry to reduce the impact on the environment. With the development of economy and technology, the state and society can invest more money to develop new products, thus providing the technical level of production, improving the efficiency of energy utilization, reducing the energy effect and accelerating the environmental improvement.

Technological progress $(\mathrm{T})$ : The technical progress in the narrow sense refers to the innovation and improvement of the input products, manufacturing technology and production technology of intermediate products, which is manifested in the use of new technology and the use of new materials. Generalized technological progress refers to the accumulation and improvement of knowledge covered by technology. The ways of technological progress are mainly shown in three aspects, including technological innovation, technology transfer and technology diffusion. Because the technological progress is an invisible variable, it can't be directly measured. Now the index of technical progress in the literature usually uses total factor progress (Total Factor Productivity, TFP), R\&D input and the number of patents three A measure of the index. Technological progress is generally reflected in the activities of innovation, and patent data as a measure of innovation is the main indicator of technological progress in existing literature. This paper also uses the number of patents instead of the technical level index to measure the level of technological progress. Technological progress can not only directly reduce energy consumption and reduce carbon emissions, but also improve the level of environmental pollution through technological progress, thus improving the environment.

Industrial structure (I): The industrial structure also called the national economy department's structure, refers to the structure of the industrial departments and their internal components in the national economy, and reflects the trend of industrial change and the proportion of the industry in a country or region. Different industrial structure leads to different types and structures of energy consumption, thus affecting the regional environment.

The adjustment of industrial structure can reduce the primary energy consumption and reduce the impact on the environment. The high proportion of the second industries in China is the main cause of energy consumption and 
environmental pollution. The upgrading and optimization of industrial structure will improve the intensity of energy consumption and reduce the degree of environmental pollution. And at the present stage, coal is the main energy consumption structure, so in order to reduce the high pollution of coal and other energy consumption, it is necessary to adjust the industrial structure and increase the investment of clean energy, such as wind energy and solar energy, and gradually get rid of China's dependence on coal and oil and other energy sources.

Financial development (F): Financial development refers to the changes in the financial structure, including shortterm changes and long-term changes. Financial development contributes to the concentration and agglomeration of capital, improves the efficiency of the use of resources, and improves the social and economic efficiency. At present, China's rapid development of finance has strengthened the role of the environment. As an indirect impact factor on the environment, financial development indicators can adjust the investment intention of the enterprise, but the effect of financial development on fog and haze has not formed a consistent view. It is assumed that the different regions are actively adjusting the financial policy to adjust the sustainable development of the economy. Therefore, the entry and development will reduce the fog and haze.

Energy prices (E): As a policy factor affecting energy consumption, the price of energy, mainly including the prices of coal, electricity and oil, can affect the consumption of energy and change the change of the environment. Energy price policy can encourage economy, promote production, promote the use of full and reasonable and effective use, and governments often adopt administrative and economic policies to intervene and regulate. The environmental policy of our country takes the energy price as the main regulation policy. Through the increase of energy price and the subsidy of new energy policy, the people's awareness of environmental protection is improved, and people will consciously save energy, use environmental protection energy and reduce the emission of pollutants.

International Trade(IT): International trade refers to the transaction of goods and services across national borders, generally including export trade and import trade in two forms, also known as import and export trade. As a world factory, China generally believes that international trade will aggravate China's environmental pollution. In order to reduce the environmental impact on the country, the developed countries often turn some of the polluted production to the developing countries, resulting in the energy consumption and environmental damage of the host countries, thus reducing the developing countries to the pollution shelters of the developed countries. International trade has a double effect on other dependent variables such as economic growth. International trade promotes economic growth, and it will also make China's furniture have more funds to govern the environment, introduce advanced equipment and technology, improve energy efficiency and clean energy utilization to reduce environmental pollution.

The rate of Urbanization (U): The meaning of urbanization is relatively broad, generally refers to the urbanization of the population. It refers to the expansion of the scale of the city and the increase in quantity, and the transformation process of the rural society mainly from agriculture to the modern cities, such as industry and service as well as the high and new technology industries. As a centralized area of resources, cities have become the concentration of energy consumption and environmental pollution, so the development level of urbanization is a major factor affecting carbon emissions. The impact of urbanization on the environment can be considered from different aspects. Population urbanization, through the improvement of people's consciousness and the change of living habits, may cause the population to produce less environmental pollution, and may also be due to the better living conditions of the city, thus reducing the consumption of the total amount of energy, thus reducing the pollution of the environment.

Fiscal decentralization (FD): Fiscal decentralization refers to the extent to which the state gives local government tax rights and expenditure responsibilities. At the same time, it allows local governments to determine the scale and structure of budgetary decision expenditure independently. Local governments can freely choose the type of policy needed, and actively participate in social management. The purpose is to provide better and more services to local governments. Therefore, fiscal decentralization can reflect the autonomy of local governments' finances. The general theory holds that the higher the fiscal decentralization, the greater the autonomy, the government does not have to adjust its behavior according to the direction of the central government, but the current research at home and abroad believes that the fiscal decentralization has different influence on the regional environment.

\section{Models}

Grey correlation analysis model of haze influence factors 
Deng Julong, a famous mathematics professor in China, mainly used the regression analysis methods in economic statistics to solve the problems of few factors and linear. The grey system has been established to solve the problems of multi factor and nonlinear. The grey system theory is a new theory that specializes in the systematic analysis of the problem of small data and information uncertainty. The method of correlation analysis fully considers all kinds of disadvantages and shortcomings of the other analytical methods, and makes up for the quantity of sample and the inadequacy of the samples, and the calculation phase. For smaller, it is also very convenient to use, and will not appear to be inconsistent with the result of qualitative analysis. The guiding principle of grey relational analysis is to judge the close relationship based on the similarity of geometrical shape of sequence curves. The closer the curve is, the greater the correlation degree between the corresponding sequences is, and vice versa. Relevance analysis is actually a quantitative analysis of the dynamic development and change process situation of a system, that is, the quantitative comparative analysis of the dynamic process development situation of the system. Because the grey system model has no special requirements and limitations to the experimental observation data, the application field of the grey system model is very wide, which can be applied to various fields.

According to the above analysis, the grey correlation analysis method is used to analyze the relationship between haze and population, economic growth, technological progress, industrial structure, financial development, energy price, international trade, urbanization rate and fiscal decentralization. The grey correlation of the corresponding time series data is established to reflect the haze and population and economic increase in China. Long, technological progress, industrial structure, financial development, energy prices, international trade, urbanization rate and fiscal decentralization, and then calculate the comprehensive clearance of China's haze and population, economic growth, technological progress, industrial structure, financial development, energy prices, international trade, urbanization rate and fiscal decentralization. United degrees systematically study their relationship.

Grey absolute correlation degree model

Suppose that the length of $\mathrm{X} 0$ is the same as that of $\mathrm{Xi}$, and the sequence is the sum of the same interval. $\mathrm{X}_{0}{ }^{0}=$ $\left(x_{0}^{0}(1), x_{0}^{0}(2), \ldots, x_{0}^{0}(n)\right), X_{i}^{0}=\left(x_{i}^{0}(1), x_{i}^{0}(2), \ldots, x_{i}^{0}(n)\right)$ is the zeroing image of the beginning point of $\mathrm{X}_{0}$ and $\mathrm{X}_{\mathrm{i}}$, and the epsilon $\mathrm{OI}$ is the grey absolute correlation between $\mathrm{X}_{0}$ and $\mathrm{X}_{\mathrm{i}}$, reflecting the similarity between the line $\mathrm{X}_{0}$ and $\mathrm{X}_{\mathrm{i}}$. In this paper, the approximation of haze and population, economic growth, technological progress, industrial structure, financial development, energy price, international trade, urbanization rate and fiscal decentralization can be expressed in this paper. It is recorded as $\varepsilon_{0 i}$.

Calculation formula:

$$
\begin{aligned}
& \varepsilon_{0 i}=\frac{1+\left|s_{0}\right|+\left|s_{i}\right|}{1+\left|s_{0}\right|+\left|s_{i}\right|+\left|s_{i}-s_{0}\right|} \\
& \left|s_{0}\right|=\left|\sum_{k=2}^{n-1} x_{0}^{0}(k)+\frac{1}{2} x_{0}^{0}(n)\right|, \quad\left|s_{i}\right|=\left|\sum_{k=2}^{n-1} x_{i}^{0}(k)+\frac{1}{2} x_{i}^{0}(x)\right| \\
& \left|s_{i}-s_{0}\right|=\left|\sum_{k=2}^{n-1}\left(x_{i}^{0}(k)-x_{0}^{0}(k)\right)+\frac{1}{2}\left(x_{i}^{0}(n)-x_{0}^{0}(n)\right)\right|
\end{aligned}
$$

Grey relative degree model

If the length of $X_{0}$ and $X_{i}$ are the same and the initial values are not zero, $X_{0}$ 'and $\mathrm{Xi}^{\prime}$ are $\mathrm{X}_{0}, \mathrm{X}_{\mathrm{i}}$ initial values, then the grey absolute correlation between $\mathrm{X}_{0}{ }^{\prime}$ and $\mathrm{X}_{\mathrm{i}}^{\prime}$ is the relative degree of grey relative degree between $\mathrm{X}_{0}$ and $\mathrm{X}_{\mathrm{i}}$, which is recorded as $r_{0 i}$.

Calculation formula:

$$
\begin{gathered}
\gamma_{o i}=\frac{1+\left|s_{0}{ }^{\prime}\right|+\left|s_{i}{ }^{\prime}\right|}{1+\left|s_{0}{ }^{\prime}\right|+\left|s_{i}{ }^{\prime}\right|+\left|s_{i}{ }^{\prime}-s_{0}{ }^{\prime}\right|} \\
\left|s_{0}{ }^{\prime}\right|=\left|\sum_{k=2}^{n-1} x_{0}^{\prime 0}(k)+\frac{1}{2} x_{0}^{\prime 0}(n)\right|, \quad\left|s_{i}{ }^{\prime}\right|=\left|\sum_{k=2}^{n-1} x_{i}^{\prime 0}(k)+\frac{1}{2} x_{i}^{\prime 0}(n)\right| \\
\left|s_{i}^{\prime}-s_{0}^{\prime}\right|=\left|\sum_{k=2}^{n-1}\left(x_{i}^{\prime 0}(k)-x_{0}^{\prime 0}(k)\right)+\frac{1}{2}\left(x_{i}^{\prime 0}(n)-x_{0}^{\prime 0}(n)\right)\right|
\end{gathered}
$$


Grey relative incidence degree is the token of the relation between the sequence $X_{0}$ and the rate of change of $X_{i}$ relative to the starting point. It removes the impact of initial conditions on sequence $X_{0}$ and $X_{i}$, and dynamically analyzes the correlation between haze and population, economic growth, technological progress, industrial structure, financial development, energy prices, international trade, urbanization rate and fiscal decentralization. If the change rate of $X_{0}$ and $X_{i}$ is closer, the greater the $r_{0 i}$ and the corresponding variables relationship are closer, otherwise the corresponding degree of correlation are lower.

Grey comprehensive correlation degree model

It is assumed that the sequence $X_{i}$ is the same length as $X_{j}$ and the initial value is not 0 , epsilon $i j, R_{i j}$ is the grey absolute correlation degree and grey relative degree of grey relative degree of $\mathrm{Xi}$ and $\mathrm{X}_{\mathrm{j}}$ respectively, and $\theta \in[0$, $1]$, then it is called the grey comprehensive correlation degree of sequence $X_{i}$ and $X_{j}$. The grey comprehensive correlation degree can fully characterize the close connection between the sequences, not only reflect the similarity between the discounted $X_{0}$ and the $X_{i}$, but also reflect the close degree of the change rate of $X_{0}$ and $X_{i}$ relative to the beginning point. It is a more comprehensive reflection of the haze and the population, economic growth, technical progress, industrial structure, financial development, and energy in China. In generaltake $\theta=0.5$ then the calculation formula is as follows:

$\rho_{i j}=0.5 \varepsilon_{i j}+0.5 \gamma_{i j}(3)$

Empirical Calculation

In order to better explain the relationship between haze and influence factors, the Beijing data is taken as an example to illustrate the calculation process of grey correlation between haze and the influencing factors. Among them, the parent sequence $X_{0}$ and the comparison sequence $X_{i}$ value are respectively. $X_{0}=(32.64,45.48,41.43,48.52,47.64,46.34,63.60,55.98,54.98,55.72,49.62,54.98,48.92,58.40,52.04,56$.

40)

$X_{I}=(1364,1385,1423,1456,1493,1538,1581,1633,1695,1755,1962,2019,2069,2115,2152,2171)$

$X_{2}=(3161.7,3596.51,4261.60,4933.89,5888.92,6705.60,7741.52,9169.39,9851.84,10940.36$,

$12407.55,13524.58,14409.22,15447.93,16376.30,17348.04)$

$X_{3}=(5905,6246,6345,8248,9005,10100,11238,14954,17747,22921,33511,40888,50511,62671$, $74661,94031)$

$X_{4}=(38.1,36.2,34.8,35 \cdot 8,37 \cdot 6,29 \cdot 5,27.8,26.8,25.7,23 \cdot 5,24,23 \cdot 1,22.7,22 \cdot 3,21 \cdot 3,19.7)$

$X_{5}=(5944.6,7202.9,9602.6,12058,113578,15335,18131,19681,23010.7,31052.9,36479.6,39660.5,43189.5,47880$. $9,53650.6,58559.4)$

$X_{6}=(100,100.5,97.1,104.7,114.2,111.4,105.5,105,115.8,88.6,110.5,108.4,98.7,97.8,98.8,93.7)$

$X_{7}=(20.0754,17.6649,15.9917,16.4638,17.9949,21.6227,24,4852,23.3490,21.6936,16.3865$,

$14.7334,12.5684,11.0323,10.5910,9.3660,7.9546)$

$X_{8}=(77.5447,78.0597,78.5554,79.0511,79.5337,83.62,84.33,84.5,84.9,85,85.96,86.2,86.2,86.3$, $86.35,86.5)$

$X_{9}=(2 \cdot 8,3,2 \cdot 8,3,3 \cdot 2,3 \cdot 1,3 \cdot 2,3 \cdot 3,3 \cdot 1,3,3,3,2 \cdot 9,3,3,3 \cdot 3)$

According to the formula (2), the absolute correlation between fog and haze in Beijing and population, economic growth, technological progress, industrial structure, financial development, energy price, international trade, urbanization rate and fiscal decentralization can be obtained.

$$
\varepsilon_{01}=0.5373, \varepsilon_{02}=0.5020, \varepsilon_{03}=0.5010, \varepsilon_{04}=0.7244, \varepsilon_{05}=0.5028, \varepsilon_{06}=0.6491,
$$

$\varepsilon_{07}=0.5028, \quad \varepsilon_{08}=0.5005, \varepsilon_{09}=0.5000$

According to the formula (3), the relative degree of Beijing fog and haze with population, economic growth, technological progress, industrial structure, financial development, energy price, international trade, urbanization rate and fiscal decentralization can be obtained.

$r_{0 i}=0.8877, \quad r_{02}=0.8260, \quad r_{03}=0.8123, \quad r_{04}=0.7709, \quad r_{05}=0.9180, \quad r_{06=} 0.8504$,

$r_{07}=0.9060, \quad r_{08}=0.7303, \quad r_{09=} 0.7263$

According to the formula (4), the comprehensive correlation of Beijing fog and haze with population, economic growth, technological progress, industrial structure, financial development, energy price, international trade, urbanization rate and fiscal decentralization can be obtained. 


$$
\begin{array}{ll}
\rho_{01}=0.7125, & \rho_{02}=0.6640, \rho_{03}=0.6567, \rho_{04}=0.7477, \rho_{05}=0.7104, \rho_{06}=0.7498, \\
\rho_{07}=0.7044, & \rho_{08}=0.6154, \rho_{09}=0.6132
\end{array}
$$

According to the above steps, we can calculate the correlation between fog and haze in other provinces and population, economic growth, technological progress, industrial structure, financial development, energy price, international trade, urbanization rate and fiscal decentralization. The grey relative degree and relative grey correlation are shown in Table 4 and table 5.

\begin{tabular}{|c|c|c|c|c|c|c|c|c|}
\hline District & $\mathrm{P}$ & A & $\mathrm{T}$ & $\mathrm{F}$ & $\mathrm{E}$ & IT & $\mathrm{U}$ & FD \\
\hline Beijing & 0.5373 & 0.5020 & 0.5010 & 0.72440 .5029 & 0.6491 & 0.5028 & 0.5005 & 0.5000 \\
\hline Tianjin & 0.6065 & 0.5043 & 0.5033 & 0.58020 .4986 & 0.5108 & 0.5294 & 0.5022 & 0.5000 \\
\hline Hebei & 0.5420 & 0.5013 & 0.5030 & 0.56390 .4851 & 0.6289 & 0.5110 & 0.5011 & 0.5001 \\
\hline Liaoning & 0.5783 & 0.5015 & 0.5017 & 0.53020 .4875 & 0.5339 & 0.5096 & 0.5004 & 0.5000 \\
\hline Shanghai & 0.5321 & 0.5023 & 0.5007 & 0.52330 .5025 & 0.5509 & 0.5329 & 0.5010 & 0.5000 \\
\hline Jiangsu & 0.5337 & 0.5009 & 0.5003 & 0.56640 .4973 & 0.5257 & 0.5340 & 0.5004 & 0.5000 \\
\hline Zhejiang & 0.5070 & 0.5003 & 0.5001 & 0.50670 .5145 & 0.7154 & 0.5229 & 0.5004 & 0.5000 \\
\hline Fujian & 0.5211 & 0.5009 & 0.5007 & 0.84860 .4921 & 0.9345 & 0.5205 & 0.5009 & 0.5000 \\
\hline Shandong & 0.5348 & 0.5009 & 0.5007 & 0.62120 .4930 & 0.5146 & 0.5062 & 0.5006 & 0.5000 \\
\hline Guangdong & 0.5075 & 0.5004 & 0.5002 & 0.53710 .5003 & 0.8017 & 0.5034 & 0.5002 & 0.5000 \\
\hline Hainan & 0.5784 & 0.5067 & 0.5710 & 0.89910 .4755 & 0.8610 & 0.5173 & 0.5158 & 0.5022 \\
\hline Shanxi & 0.5363 & 0.5018 & 0.5046 & 0.83240 .4864 & 0.7384 & 0.5033 & 0.5011 & 0.5003 \\
\hline Jilin & 0.6450 & 0.5023 & 0.5056 & 0.62990 .4911 & 0.6041 & 0.5134 & 0.5017 & 0.5001 \\
\hline Heilongjiang & 0.6397 & 0.5008 & 0.5011 & 0.96270 .4684 & 0.7281 & 0.5253 & 0.5004 & 0.5000 \\
\hline Anhui & 0.8843 & 0.5028 & 0.5022 & 0.58660 .4921 & 0.5949 & 0.5179 & 0.5014 & 0.5001 \\
\hline Jiangxi & 0.5413 & 0.5029 & 0.5076 & 0.90910 .4867 & 0.6754 & 0.5035 & 0.5019 & 0.5002 \\
\hline Henan & 0.7356 & 0.5013 & 0.5018 & 0.69950 .4866 & 0.5443 & 0.5997 & 0.5007 & 0.5001 \\
\hline Hubei & 0.5682 & 0.5009 & 0.5008 & 0.71680 .5289 & 0.5209 & 0.5075 & 0.5004 & 0.5000 \\
\hline Hunan & 0.6189 & 0.5018 & 0.5021 & 0.57840 .4861 & 0.5242 & 0.5046 & 0.5010 & 0.5001 \\
\hline Inner Mongolia & 0.5124 & 0.5002 & 0.5015 & 0.56450 .4115 & 0.8894 & 0.5203 & 0.5010 & 0.5007 \\
\hline Guangxi & 0.8521 & 0.5030 & 0.5103 & 0.62010 .4909 & 0.6769 & 0.5261 & 0.5064 & 0.5002 \\
\hline Chongqing & 0.7247 & 0.5021 & 0.5011 & 0.76410 .4889 & 0.5487 & 0.5198 & 0.5025 & 0.5001 \\
\hline Sichuan & 0.5156 & 0.5007 & 0.5004 & 0.64200 .4790 & 0.7506 & 0.5050 & 0.5015 & 0.5000 \\
\hline Guizhou & 0.5610 & 0.5030 & 0.5049 & 0.64600 .4895 & 0.6883 & 0.5043 & 0.5016 & 0.5002 \\
\hline Yunnan & 0.5094 & 0.5012 & 0.5027 & 0.52380 .4950 & 0.9626 & 0.5016 & 0.5020 & 0.5002 \\
\hline Shanxi & 0.5223 & 0.5004 & 0.5005 & 0.67310 .4279 & 0.7078 & 0.5019 & 0.5012 & 0.5001 \\
\hline Gansu & 0.5283 & 0.5009 & 0.5020 & 0.97230 .4303 & 0.6457 & 0.5093 & 0.5033 & 0.5003 \\
\hline Ningxia & 0.5639 & 0.5068 & 0.5129 & 0.82540 .4883 & 0.7092 & 0.5079 & 0.5105 & 0.5003 \\
\hline Qinghai & 0.6493 & 0.5131 & 0.5690 & 0.93890 .4835 & 0.8318 & 0.5052 & 0.5080 & 0.5018 \\
\hline Xinjiang & 0.5156 & 0.5022 & 0.5050 & 0.72550 .4681 & 0.9685 & 0.5217 & 0.5015 & 0.5004 \\
\hline
\end{tabular}

Tab.1 Grey absolute correlation between haze and impact factors in major provinces

Tab.2 Grey relative associated degree between haze and impact factors in the major provinces

\begin{tabular}{llllllllll}
\hline District & P & A & T & I & F & E & IT & U & FD \\
\hline Beijing & 0.8877 & 0.8260 & 0.8123 & 0.7709 & 0.9180 & 0.8504 & 0.9060 & 0.7303 & 0.7263 \\
\hline
\end{tabular}




\begin{tabular}{|c|c|c|c|c|c|c|c|c|c|}
\hline Tianjin & 0.8924 & 0.7917 & 0.7404 & 0.8813 & 0.9616 & 0.8595 & 0.9764 & 0.7463 & 0.6913 \\
\hline Hebei & 0.8771 & 0.8458 & 0.8915 & 0.8802 & 0.8414 & 0.8801 & 0.8219 & 0.8557 & 0.8168 \\
\hline Liaoning & 0.8260 & 0.9172 & 0.9517 & 0.8245 & 0.8682 & 0.8226 & 0.9736 & 0.7825 & 0.7977 \\
\hline Shanghai & 0.8853 & 0.9013 & 0.6638 & 0.8152 & 0.9454 & 0.8153 & 0.9022 & 0.7882 & 0.6150 \\
\hline Jiangsu & 0.8528 & 0.8328 & 0.6182 & 0.8558 & 0.9758 & 0.8377 & 0.8044 & 0.7742 & 0.6017 \\
\hline Zhejiang & 0.9578 & 0.7642 & 0.6133 & 0.9270 & 0.8677 & 0.9193 & 0.8444 & 0.7552 & 0.6231 \\
\hline Fujian & 0.8704 & 0.8696 & 0.7835 & 0.8898 & 0.9961 & 0.8328 & 0.9350 & 0.7985 & 0.6871 \\
\hline Shandong & 0.8530 & 0.8274 & 0.7593 & 0.8735 & 0.8950 & 0.8446 & 0.9277 & 0.8280 & 0.6932 \\
\hline Guangdong & 0.8421 & 0.8643 & 0.7542 & 0.8201 & 0.8197 & 0.7964 & 0.9923 & 0.7549 & 0.6425 \\
\hline Hainan & 0.8289 & 0.9246 & 0.8561 & 0.8913 & 0.8261 & 0.8002 & 0.9096 & 0.9309 & 0.9105 \\
\hline Shanxi & 0.8786 & 0.7979 & 0.8433 & 0.9070 & 0.8307 & 0.8798 & 0.9799 & 0.7518 & 0.8327 \\
\hline Jilin & 0.8396 & 0.8698 & 0.9995 & 0.8535 & 0.7849 & 0.8139 & 0.7421 & 0.6515 & 0.6474 \\
\hline Heilongjiang & 0.9070 & 0.8613 & 0.8596 & 0.8830 & 0.8542 & 0.8998 & 0.9588 & 0.8026 & 0.7948 \\
\hline Anhui & 0.8437 & 0.8734 & 0.7127 & 0.8638 & 0.8938 & 0.8523 & 0.9509 & 0.8250 & 0.6706 \\
\hline Jiangxi & 0.8116 & 0.8854 & 0.9591 & 0.8932 & 0.8028 & 0.8137 & 0.9244 & 0.8063 & 0.8385 \\
\hline Henan & 0.8001 & 0.9055 & 0.8533 & 0.8337 & 0.7981 & 0.8032 & 0.8411 & 0.8243 & 0.7463 \\
\hline Hubei & 0.9290 & 0.7914 & 0.7048 & 0.9017 & 0.8336 & 0.9245 & 0.9400 & 0.7638 & 0.6894 \\
\hline Hunan & 0.8350 & 0.8732 & 0.8421 & 0.8543 & 0.8431 & 0.8360 & 0.9441 & 0.8134 & 0.8107 \\
\hline Inner Mongolia & 0.9822 & 0.6788 & 0.8657 & 0.9390 & 0.9099 & 0.9682 & 0.8562 & 0.6929 & 0.9431 \\
\hline Guangxi & 0.7886 & 0.9252 & 0.9404 & 0.8119 & 0.8353 & 0.8006 & 0.9273 & 0.6547 & 0.8646 \\
\hline Chongqing & 0.8809 & 0.8196 & 0.6604 & 0.9216 & 0.9527 & 0.8806 & 0.9383 & 0.8089 & 0.6699 \\
\hline Sichuan & 0.8458 & 0.8668 & 0.7248 & 0.8651 & 0.8990 & 0.8620 & 0.8156 & 0.9062 & 0.6901 \\
\hline Guizhou & 0.8829 & 0.8160 & 0.8353 & 0.9065 & 0.9753 & 0.8972 & 0.9459 & 0.7800 & 0.8171 \\
\hline Yunnan & 0.9077 & 0.8639 & 0.9109 & 0.8885 & 0.9796 & 0.9026 & 0.9615 & 0.8565 & 0.7869 \\
\hline Shanxi & 0.9674 & 0.6994 & 0.6938 & 0.9173 & 0.9800 & 0.9511 & 0.9832 & 0.7504 & 0.7439 \\
\hline Gansu & 0.9849 & 0.7874 & 0.7957 & 0.9945 & 0.9737 & 0.9584 & 0.9453 & 0.8394 & 0.8193 \\
\hline Ningxia & 0.9178 & 0.6948 & 0.7357 & 0.9176 & 0.8780 & 0.9398 & 0.9373 & 0.7708 & 0.8228 \\
\hline Qinghai & 0.8502 & 0.8602 & 0.9876 & 0.8842 & 0.8623 & 0.8507 & 0.9525 & 0.7716 & 0.9748 \\
\hline Xinjiang & 0.9758 & 0.8065 & 0.8310 & 0.9599 & 0.9299 & 0.9157 & 0.7680 & 0.7947 & 0.8823 \\
\hline
\end{tabular}

According to the above steps, the comparison results of grey comprehensive correlation between Beijing fog and haze with population, economic growth, technological progress, industrial structure, financial development, energy price, international trade, urbanization rate and fiscal decentralization are compared, as shown in Table 6.

Tab.3 Grey comprehensive correlation degree between haze and impact factors in major provinces

\begin{tabular}{|c|c|c|c|c|c|c|c|c|c|}
\hline District & & A & $\mathrm{T}$ & $\mathrm{I}$ & $\mathrm{F}$ & $\mathrm{E}$ & IT & $\mathrm{U}$ & FD \\
\hline Beijing & 0.7125 & 0.6640 & 0.6567 & 0.7477 & 0.7104 & 0.7498 & 0.7044 & 0.6154 & 0.6132 \\
\hline Tianjin & 0.7494 & 0.6480 & 0.6219 & 0.7073 & 0.7301 & 0.6851 & 0.7529 & 0.6243 & 0.5957 \\
\hline Hebei & 0.7095 & 0.6736 & 0.6972 & 0.7221 & 0.6767 & 0.7546 & 0.6665 & 0.6784 & 0.6585 \\
\hline Liaoning & 0.7022 & 0.7093 & 0.7267 & 0.6774 & 0.6638 & 0.6782 & 0.7416 & 0.6414 & 0.6489 \\
\hline Shanghai & 0.7087 & 0.7018 & 0.5823 & 0.6693 & 0.6387 & 0.6831 & 0.7175 & 0.6446 & 0.5575 \\
\hline Jiangsu & 0.6933 & 0.6668 & 0.5593 & 0.7111 & 0.7240 & 0.6817 & 0.6692 & 0.6374 & 0.5509 \\
\hline Zhejiang & 0.7324 & 0.6322 & 0.5567 & 0.7168 & 0.6910 & 0.8174 & 0.6836 & 0.6278 & 0.5616 \\
\hline Fujian & 0.6958 & 0.6852 & 0.6421 & 0.8693 & 0.7441 & 0.8837 & 0.7277 & 0.6497 & 0.5936 \\
\hline Shandong & 0.6939 & 0.6642 & 0.6300 & 0.7344 & 0.6940 & 0.6796 & 0.7170 & 0.6643 & 0.5966 \\
\hline Guangdong & 0.6748 & 0.6824 & 0.6272 & 0.6786 & 0.6600 & 0.7991 & 0.7479 & 0.6276 & 0.5713 \\
\hline Hainan & 0.7036 & 0.7157 & 0.7136 & 0.8952 & 0.6508 & 0.8306 & 0.7134 & 0.7233 & 0.7064 \\
\hline Shanxi & 0.7074 & 0.6499 & 0.6739 & 0.8697 & 0.6586 & 0.8091 & 0.7416 & 0.6265 & 0.6665 \\
\hline Jilin & 0.7423 & 0.6860 & 0.7526 & 0.7417 & 0.6380 & 0.7170 & 0.7225 & 0.6447 & 0.6878 \\
\hline Heilongjiang & 0.7734 & 0.6810 & 0.6803 & 0.9228 & 0.6613 & 0.8139 & 0.7421 & 0.6515 & 0.6474 \\
\hline Anhui & 0.8640 & 0.6881 & 0.6074 & 0.7252 & 0.6930 & 0.7236 & 0.7344 & 0.6632 & 0.5853 \\
\hline Jiangxi & 0.6765 & 0.6941 & 0.7333 & 0.9011 & 0.6447 & 0.7445 & 0.7140 & 0.6541 & 0.6693 \\
\hline Henan & 0.7679 & 0.7034 & 0.6775 & 0.7666 & 0.6423 & 0.6737 & 0.7204 & 0.6625 & 0.6232 \\
\hline Hubei & 0.7486 & 0.6462 & 0.6028 & 0.8092 & 0.6813 & 0.7227 & 0.7237 & 0.6321 & 0.5947 \\
\hline Hunan & 0.7270 & 0.6875 & 0.6721 & 0.7163 & 0.6646 & 0.6801 & 0.7243 & 0.6572 & 0.6554 \\
\hline Inner Mongolia & 0.7473 & 0.5895 & 0.6836 & 0.7518 & 0.6607 & 0.9288 & 0.6882 & 0.5969 & 0.7219 \\
\hline Guangxi & 0.8203 & 0.7141 & 0.7254 & 0.7160 & 0.6631 & 0.7387 & 0.7267 & 0.5806 & 0.6824 \\
\hline Chongqing & 0.8028 & 0.6609 & 0.5807 & 0.8428 & 0.7208 & 0.7416 & 0.7291 & 0.6557 & 0.5850 \\
\hline Sichuan & 0.6807 & 0.6838 & 0.6126 & 0.7536 & 0.6890 & 0.8063 & 0.6603 & 0.7038 & 0.5951 \\
\hline Guizhou & 0.7219 & 0.6595 & 0.6701 & 0.7763 & 0.7324 & 0.7928 & 0.7251 & 0.6408 & 0.6587 \\
\hline Yunnan & 0.7085 & 0.6826 & 0.7068 & 0.7061 & 0.7373 & 0.9326 & 0.7316 & 0.6792 & 0.6436 \\
\hline Shanxi & 0.7449 & 0.5999 & 0.5971 & 0.7952 & 0.7040 & 0.8295 & 0.7425 & 0.6258 & 0.6220 \\
\hline Gansu & 0.7566 & 0.6441 & 0.6488 & 0.9833 & 0.7020 & 0.8020 & 0.7273 & 0.6713 & 0.6598 \\
\hline Ningxia & 0.7408 & 0.6008 & 0.6243 & 0.8715 & 0.6832 & 0.8245 & 0.7226 & 0.6406 & 0.6616 \\
\hline Qinghai & 0.7498 & 0.6866 & 0.7783 & 0.9115 & 0.6729 & 0.8413 & 0.7289 & 0.6398 & 0.7383 \\
\hline Xinjiang & 0.7457 & 0.6544 & 0.6680 & 0.8427 & 0.6990 & 0.9421 & 0.6449 & 0.6481 & 0.6914 \\
\hline
\end{tabular}

\section{Conclusions}


According to the grey correlation degree in table 4, 5 and 6, it can be concluded that the correlation between haze and different influencing factors in different regions of China is different. The grey absolute correlation degree of haze and energy price is generally high from the static point of view, and the highest is 0.9685 and 0.9626 in Xinjiang and Yunnan. There are second factors in the absolute correlation between industrial structure and haze. The third factor is population in turn. The absolute correlation degree between haze and fiscal decentralization is all low, most of which is 0.5000 . In order to eliminate the influence of the initial factors, it can be seen from the angle of grey relative correlation that the fog and haze in most regions have the highest grey absolute correlation with the energy price, but the relative degree of haze and economic growth in areas with relatively developed economy, such as Beijing and Shanghai, is lower than the haze and urbanization rate and population.

The grey haze of 10 provinces in Shandong, Shanxi and Heilongjiang and other provinces has the greatest grey comprehensive correlation from the specific provincial level; the grey haze and the energy price in 11 provinces of Beijing, Hebei and Zhejiang have the highest grey comprehensive correlation degree; the fog haze in Zhejiang, Hunan and Guangxi is higher in relation to the population; The gray comprehensive correlation degree of regional financial development and haze is the strongest; at present, China is in the stage of rapid development of urbanization, but the relationship between haze and urbanization in Beijing and Tianjin is not high, and the grey haze and fiscal decentralization grey comprehensive correlation degree is low. It can be seen that the correlation of haze and influence factors in different provincial regions is completely different, the economic development stage and the economic development characteristics are different, the haze and the influence factors are differentso we can't adopt the unified haze control policy in the whole country.

The results of grey correlation system analysis are basically consistent with the actual situation. The most regional fog haze has the highest comprehensive correlation degree with industrial structure and energy price, followed by the factors of population and international trade, and the relationship between haze and haze does not reach the expected goal among the main factors affecting haze in China. The gray relative degree of haze and economic growth is relatively small in economically developed regions. The grey relative degree of the financial development is high, but the degree of absolute correlation is low and the energy price is just the opposite. And the energy prices in all provinces of our country have great influence on the haze. It should be paid enough attention to, and it is still effective to restrain the haze by regulating the energy price. From the overall grey comprehensive correlation degree, the relationship between the haze and the urbanization rate is lower in the main provinces in the country, and the economic development of most provinces has a strong correlation with the haze.

\section{Policy and Recommendations}

According to Coase's theory, environmental governance is how to define environmental responsibility. Our country has a vast territory so we should make sure the goal of smog control in each province to realize the green development of the whole national economy according to the actual situation of each province. All regions should realize the emission reduction target and develop green economy according to the relationship between haze and influencing factors so as to realize the construction of beautiful China. From the results of this study, we can see that the correlation characteristics between haze and influencing factors are not the same in different regions. Therefore, we should consider the following aspects to reduce haze related policies. First of all the overall industrial structure of China is closely related to haze and is an important factor associated with haze.

This is due to the specific historical stage of China's economic development and in line with the principle of being a responsible big country. We will not take the old way of first development and post governance. The central government departments should pay attention to the heterogeneity of local specific development because of the different economic development in different provinces and regions in China. According to the specific characteristics of different provinces and regions, we should consider the characteristics and actual conditions of different stages of economic development in different regions, and combine the industrial structure conditions of various regions to formulate different provincial regions. We should adhere to the principle of common but differentiated haze control, and establish and implement measures and policies for haze control according to local conditions.

The second one is that most of the provincial energy prices and haze absolute correlation degree is higher, should actively adopt the energy price adjustment to reduce the fog and haze, through the reasonable price control to realize the problem of energy saving and reduction. 
We should change the past behavior of managing the market solely through price regulation, and guide consumers to use clean energy actively through universal education. At the same time, fiscal policy measures are taken to reflect the social costs, and to promote the governance targets of local governments through the establishment of the resource management system and the release of emission data. At the same time, each region combines the green development path suitable for its own characteristics, formulating the targeted and effective policy measures, speeding up the haze control in the region, and making our country steadily enter the road of green economic development.

The third is to reduce the fog and haze, technological progress is the key. At present, the United States, Germany and Japan and other developed countries regard low-carbon technology and energy technology innovation as an important means to reduce environmental pollution. It can be seen from the analysis that the relationship between haze and technological progress is low in China.

The reality of China is the energy structure which is still dominated by coal in the short term, so it can only promote the realization of environmental protection targets through technological progress. Therefore, we must speed up scientific and technological innovation to catch up with the advanced international level, formulate effective policies and measures to encourage all industries to speed up clean energy substitution, and realize the sustainable development of China through the combination of technological innovation and rapid alternative development of clean energy.

The impact of population on haze cannot be ignored. In order to ensure the survival needs of future generations, the protection of resources and environment is a top priority for sustainable development. In terms of provincial development, we should reasonably control population size according to provincial haze and population correlation. Change the way of personal life, change the past waste of energy and change into "contentment and saving" as a fashionable material life concept. By providing benefit stimulation and publicizing the concept of green development, the whole people's awareness of environmental protection and environmental protection should be raised, and a positive mechanism of active response and conscientious compliance by the whole people in the whole society is formed, and a model of the stock based economic and social development is built.

China will still take industry as the leading sector of economic development in the future. The government departments at all levels should actively take measures to promote the financial development policy of the low carbon industry and the green industry due to the relatively high degree of relative correlation and comprehensive correlation between the financial development and the haze, formulate practical and feasible financial development measures, and guide the elimination of the backward production capacity sector and optimize the energy consumption knot through the policy. It is designed to reduce the haze in the high energy consumption industrial sector. According to the actual situation of various regions to adjust the industrial structure to achieve industrial upgrading, the formulation of different levels of haze management targets, coordinated development of regional economy, and improve the enthusiasm of regional fog and haze governance. It is necessary for us to strengthen the construction of regional green economic cooperation, strengthen the construction of industrial innovation cluster, and form a certain scale and advanced low energy consumption and low pollution industry. We should strengthen cooperation with leading countries and advanced enterprises in the world, do a good job in importing and going out, and speed up the development of China's green industry. It is urgent to reduce the amount of haze while develop low carbon urbanization is a serious problem facing our country.

Governments at all levels and relevant departments should make clear the transformation of China's low carbon economy, actively take corresponding measures to promote the process of urbanization in China, build a resourcesaving and compact green city, and play the important guiding role of local government in the construction of green cities in China. The government departments select cities with better haze control, take the leading role of the pioneers, formulate action plans, and develop green urban features such as green traffic and green buildings. For the new construction projects, we should take strict examination and approval to ensure that our country can achieve green development and urbanization and coordinate all aspects of the relationship.

China should actively learn from the experience and lessons of the haze management in the world. In view of the causes of the severe haze areas and the main factors, we should refer to the policies and measures of the developed countries and take the way of state intervention. For example, the air pollution control law of the United States Congress, the air pollution control act of 1955, increased PM2.5 as a national standard for environmental air quality in 1997, and monitored the highest and lowest concentrations of PM2.5 for 24 hours in 2006. 
According to different stages of the environmental law of industrial development, clean air act and environmental protection regulations, different governance acts are issued in different stages of the UK. Fog and haze indicators are made according to different regions, industries and enterprises. At the same time, the fog and haze can be reported to the people in real time. Not only the haze pollution data can be seen on the web site but also the haze pollution. The dyeing index and varying index can be used to visualize the haze pollution value and trend of all monitoring points on the map app.

The strategy of harnessing fog and haze should establish a unified management institution and establish regional environmental governance institutions to conduct a coordinated and unified management. At the same time, the regional development should be combined with environmental and environmental protection indicators. The air quality research center, based on the terrain and climate characteristics of different regions, establishes the air pollution management parameters in different regions. Legal norms and close monitoring are important indicators for the overall assessment of the local community.

For the whole of our country, we should use the idea of solving the problem of people's livelihood to guide the progress of technology, industrial structure adjustment and urbanization, make the work focus and target of the different development stages of the region, strictly check the index, strengthen the supervision of environmental law enforcement and pursue the responsibility to the end, implement the mechanism of joint control and joint defense, and deepen regional cooperation. To achieve cross regional cooperation to cope with the haze problem, to share the cost of governance rationally, actively promote the process of haze management, and actively participate in international cooperation to promote the sustainable economic growth of low pollution.

\section{References}

Battelle Memorial Institute Center for International Earth Science Information Network-CIESIN-Columbia University, Global Annual Average PM 2.5 Grids from MODIS and MISR Aerosol Optical Depth(AOD).Palisades[M].NY: NASA Socioeconomic Data and Applications Center(SEDAC), 2016.

Crompton P, Wu Y R. Energy Consumption in China: Past Trends and Future Directions[J]. Energy Economics, 2005, 27(1):195-208.

Frank A AM de Leeuw, Nicolas Moussiopoulos, Peter Sahm, et al. Urban Air Quality in Larger Conurbations in the European Union[J]. Environmental Modeling and Software, 2001(4):399-414.

Hui Ying, Mao Pei, Dai Hongwei. An Empirical of the Spatial Distribution of Haze Pollution and Its Influence Factors in Hebei Province[J].Economy and Mangement, 2018,32(3):65-71.

Jones C T. A Dynamic Analysis of Interfuel Substitution in U.S. Industrial Energy Demand[J]. Journal of Business and Economic Statistics, 1995,13(4):459-465.

LengYanli, Du Sizheng. Energy Price Distortion and Haze Pollution: The Evidence from China[J]. Industrial Economics Research, 2016(1):71-79.

Li Bin, Lu Juan. Leaders' Personal Characteristics, Local Corruption and Haze Changes[J].Statistics \& Decision, 2012(18):25-28.

Li Jian, Zhou Hui. Correlation Analysis of Carbon Emission Intensity and Industrial Structure in China[J].China Population Resources and Environment,2012,22(1):7-14.

Li Kaijie, Qu Ruxiao. The Effect of Technological Change on China's Carbon Dioxide Emission: An Empirical Analysis Based on the Vector Error Correction Model[J]. China Soft Science, 2012(6):51-58.

Li Zhenyu, Huang Ge, Li Dingjie, Ren Jing. The Cause Analysis of Beijing Haze Weather Formation from Energy Consumption Structure and Prevention and Control Measures [J]. Petroleum \& Petrochemical Today, 2013,1(6):11-16.

Ma Limei, Zhang Xiao. The Spatial of China's Haze Pollution and the Impact from Economic Change and Energy Structure [J]. China Industrial Economics， 2014(4):19-31.

Nurhidayah L. Legislation, regulations, and policies in Indonesia relevant to addressing land/forest fires and transboundary haze pollution: A critical evaluation[J]. American Journal of Physiology Renal Physiology, 2013,293(4):1332-1341.

Romero Avila, D 2008.Convergence in Carbon Dioxide Emissions among Industrialized Countries Revisited[J]. Energy Economics,2008,30(5):2265-2282.

Selden T M, Song D Q. Neoclassical Growth the J Curve for Abatement, and the Inverted-U Curve for Pollution[J]. Journal of Environmental Economics and Management, 1995(29):162-168. 
Solow R M. Technical change and the aggregate production function[J]. Review of Economics and Statistics, 1957 (39): 312-320.

Tong Xin. On the Convergence of China's Regional Carbon Emissions[J].Journal of Northeastern University, 2017,19(4):364-370.

Wang Meixia. Temporal and Spatial Distribution Characteristics of Haze Population and Its Driving Factors[J].Journal of Shanxi University(Philosophy and Social Sciences Edition), 2017(3):1-10.

Wang Yichen, Shen Yingchun. Spillover Effect Analysis of the Spatial Characteristics and Influencing Factors of Bejing_Tianjin_Hebei[J]. China Population Resources and Environment, 2017, 27(5):41-44.

Wu Xun, Wang Jie. Fiscal Decentralization, Environmental Protection Expenditure and Haze Pollution [J]. Resources Science, 2015(9):851-861.

Zheng Guojiao, Yang Laike. Solutions of Fog and Haze Weather from the perspective of Economic Development [J].Ecological Economy, 2015, 31(9):34-38.

Zhuang Guiyang, Zhou Weiduo, Bo Fan. Theoretical Basis and Innovative Mechanism for Collaborative Governance on Haze around Beijing-Tianjin-Hebei Region[J]. Journal of China University of Geosciences(Social Sciences Editon), 2017,17(5):10-17. 